University of New Hampshire

University of New Hampshire Scholars' Repository

Kinesiology Scholarship

Kinesiology

4-1-2011

\title{
Low strength is related to diminished ground reaction forces and walking performance in older women
}

\author{
Dain P. LaRoche \\ University of New Hampshire, Durham, dain.laroche@unh.edu \\ Erica D. Millet \\ University of New Hampshire, Durham \\ Rachel J. Kralian \\ University of New Hampshire, Durham
}

Follow this and additional works at: https://scholars.unh.edu/kinesiology_facpub

Comments

The publisher's final edited version of this article is available at: https://dx.doi.org/10.1016/j.gaitpost.2011.02.022

\section{Recommended Citation}

D. P. LaRoche, Millett, E.D., Kralian, R.J. (2011) Lower-limb strength relates to ground reaction forces and walking performance in older women. Gait \& Posture. 33(4): 668-672.

This Article is brought to you for free and open access by the Kinesiology at University of New Hampshire Scholars' Repository. It has been accepted for inclusion in Kinesiology Scholarship by an authorized administrator of University of New Hampshire Scholars' Repository. For more information, please contact

Scholarly.Communication@unh.edu. 


\title{
Low strength is related to diminished ground reaction forces and walking performance in older women
}

\author{
Dain P. LaRoche, Erica D. Millett, and Rachel J. Kralian \\ Department of Kinesiology, University of New Hampshire, Durham, NH
}

\begin{abstract}
The purpose of this study was to determine how lower-limb strength in older women affected gait speed, supportive forces, spatial, and temporal aspects of walking gait. Twenty-four women between $65-80$ yr performed maximal voluntary isometric contractions for the knee extensors (KE), knee flexors (KF), ankle plantarflexors (PF) and ankle dorsiflexors (DF) and were separated into low strength and normal strength groups using a KE torque threshold of $1.5 \mathrm{Nm} \mathrm{kg}^{-1}$. They walked at both a standard speed of $0.8 \mathrm{~m} \mathrm{~s}^{-1}$ and at a self-selected maximal speed on an instrumented treadmill that recorded vertical ground reaction forces (vGRF) and spatiotemporal gait measures. Older women with low strength had 30\% lower KE maximal torque, 36\% lower PF maximal torque, $34 \%$ lower KE rate of torque development (RTD) and 30\% lower KF RTD. Low strength women demonstrated slower maximal walking speeds $\left(1.26 \pm 0.20 \mathrm{vs} .1 .56 \pm 0.20 \mathrm{~m} \mathrm{~s}^{-1}\right)$, lower vGRF during weight acceptance $(1.15 \pm 0.10$ vs. $1.27 \pm 0.13 \mathrm{BW})$, lower weight acceptance rates $\left(11.3 \pm 0.5\right.$ vs. $\left.17.0 \pm 5.5 \mathrm{BW} \mathrm{s}^{-1}\right)$, slower stride rates, shorter stride lengths, and longer footground and double-limb support times (all $\mathrm{P}<0.05$ ). Maximal gait speed was strongly correlated to peak vGRF and rate $(r=0.60-0.85, P<0.01)$ and moderately related to lower-limb strength $(r$ $=0.42-0.60, \mathrm{P}<0.05)$. In older women with low strength, diminished peak vGRFs were associated with slower walking speeds putting them at risk for mobility limitation, disability, poor health, and loss of independence.
\end{abstract}

\section{Keywords}

MOBILITY; AGING; FALL RISK; POWER; DISABILITY; SPPB; GAIT SPEED; KINETICS

\section{INTRODUCTION}

In older adults lower-limb weakness has been related to poor mobility [1-4], increased fall risk [5-7], hospitalization [8], loss of independence and mortality [9, 10]. Generally, young adults possess lower-limb strength that allows them to produce the forces required to walk and run at moderate to fast velocities. Beginning in middle age, muscular strength declines at a rate of approximately $15 \%$ per decade [11] until older adults do not have the requisite strength needed to propel themselves to functionally significant speeds. When walking

(C) 2011 Elsevier B.V. All rights reserved.

Corresponding Author: Dain P. LaRoche, Ph.D., 124 Main Street, Durham, NH 03824, (603)-862-4859, (603)-862-0154, Dain.LaRoche@unh.edu .

Publisher's Disclaimer: This is a PDF file of an unedited manuscript that has been accepted for publication. As a service to our customers we are providing this early version of the manuscript. The manuscript will undergo copyediting, typesetting, and review of the resulting proof before it is published in its final citable form. Please note that during the production process errors may be discovered which could affect the content, and all legal disclaimers that apply to the journal pertain.

CONFLICT OF INTEREST

There is no conflict of interest. 
speed declines to the point that mobility is impaired, older adults are at a risk for disability, dependency, disease, and death $[9,10,12]$. Thus, a unilateral knee extensor (KE) torque threshold of approximately $1.5 \mathrm{Nm} \mathrm{kg}^{-1}$ has been proposed to identify those who are at risk for mobility limitation due to low strength $[4,13,14]$. These studies demonstrated that older adults with low KE strength are at increased risk for mobility limitation but did not investigate the connection between strength and the capacity to generate supportive forces during walking.

In adult humans, walking velocities generally range from $0.5-2 \mathrm{~m} \mathrm{~s}^{-1}$ and as the speed of walking increases, the vertical ground reaction forces (vGRF) increase linearly [15]. It has been suggested by Winter [16] that the sum of the hip, knee and ankle extensor moments (i.e. support moment) "represents the net tendency of the lower limb to push away from the ground". Hof [17] expanded upon this concept and showed that the support moment was proportional to the product of the ground reaction force vector and its moment arm acting at the knee. Because the largest component of the ground reaction force is routinely the vertical component [18], it should relate well to the support moment and the forces generated by lower-limb muscles. In the current study's simplified approach, the vertical component of the ground reaction force was used as a summative measure to represent the supportive forces of the lower-limb and was examined in relation to strength in older women. Use of the vGRF and basic gait parameters to evaluate lower-extremity performance may become increasingly useful as the clinical use of force sensing plates, gait mats, insole systems, and instrumented treadmills increases.

The purpose of this study was to better characterize why poor lower-limb strength is related to reduced walking speed in older adults by testing how strength affected supportive forces, spatial, and temporal aspects of walking gait. It was hypothesized that those with low KE strength would also demonstrate low knee flexor (KF), plantarflexor (PF), and dorsiflexor (DF) strengths. The authors theorized that poor lower-limb maximal joint torques and rates of torque development (RTD) would translate into lower vGRF and rates during walking, limiting maximal walking speed.

\section{METHODS}

\section{Participants}

Women between the ages of 65-80 yr were recruited from the local community and were separated into low and normal strength groups (described below). To participate, they had to be living independently, free of major neurological, muscular, skeletal or cardiovascular disease, and able to walk unassisted. Twenty-four women met these criteria, obtained consent from their physicians, and gave their own written, informed consent to participate in the research. Participant descriptive characteristics can be seen in Table 1. The research protocol was approved for the use of human subjects by the university's Institutional Review Board.

\section{Procedures}

During the first visit to the laboratory, anthropometric measurements were taken, then subjects completed a Short Physical Performance Battery (SPPB) which included a timed four-meter walk at the participant's habitual gait speed, a balance test, and time to complete five chair rises [10]. Physical activity was assessed using the Rapid Assessment of Physical Activity with scores ranging from 1 (sedentary) to 7 for aerobic activity ( $\geq 6=$ active) and 0 (no participation) to 3 (participates in both exercises) for strength and flexibility [19]. Next, participants were habituated to both the strength and treadmill walking protocols. Two to seven days later, participants returned to the laboratory for the second visit. The strengths of 
the KE, KF, PF, and DF were determined followed by treadmill walking at both standard and self-selected maximal speeds. Using the proposed $\mathrm{KE}$ torque threshold of $1.5 \mathrm{Nm} \mathrm{kg}^{-1}$ participants were separated into low strength and normal strength groups. Thirteen women had maximal knee extensor torques below $1.5 \mathrm{Nm} \mathrm{kg}^{-1}$ and were assigned to the low strength group, and eleven women had maximal knee extensor torques above $1.5 \mathrm{Nm} \mathrm{kg}^{-1}$ and were assigned to the normal strength group.

\section{Strength measurement}

Measurements of maximal torque and RTD were conducted using computerized dynamometry (HUMAC Norm, CSMI, Stoughton, MA, USA). Participants performed maximal voluntary isometric contractions for the KE, KF, PF, and DF. Each joint action was tested twice with $30 \mathrm{~s}$ of recovery provided between trials. The analog torque output of the dynamometer was sampled at $1 \mathrm{kHz}$ using a data acquisition system and associated software (BIOPAC MP100, Biopac Systems, Inc., Goleta, California, USA). Maximal torque was determined as the highest torque produced over the two trials and maximal RTD was determined as the greatest instantaneous rate of change in the torque vs. time curve as described in detail previously [7].

\section{Gait assessment}

To assess the vGRF, spatial, and temporal components of walking gait, participants walked on an instrumented treadmill (Gaitway II, Kistler Instrument Corp., Amherst, NY, USA) at two different speeds; $0.83 \mathrm{~m} \mathrm{~s}^{-1}$ and a self-selected, maximal, comfortable walking speed. This allowed comparisons between groups at a standard submaximal speed and a near maximal speed. Subjects walked at each speed for two minutes during which time the vGRF and center of pressure were sampled from the treadmill's force plates at $100 \mathrm{~Hz}$ using a personal computer, and accompanying software (Gaitway v.2.0.8.50, Kistler Instrument Corp., Amherst, NY, USA). At each speed, gait variables were recorded over ten sequential strides and averaged across both strides and legs for analysis. If during foot strike, the front foot failed to completely cross the threshold between the front and back force plates during any step, the trial was discarded. The first trial that included ten successful foot strikes for each leg was used for analysis.

Gait variables were calculated using the treadmill's software as described next. The intraclass correlation coefficient $\left(r_{\mathrm{xx}}\right)$ and standard error of the measurement (SEM) are given in parentheses as previously determined in the authors' laboratory with older subjects. In the automated analysis, the stance phase was separated into a weight acceptance period $\left(1^{\text {st }}\right.$ half of the foot-ground contact time) and push-off period $\left(2^{\text {nd }}\right.$ half of the foot-ground contact time) similar to the methods of Stacoff et al. [20]. Peak vGRF were determined during weight acceptance $\left(\mathrm{F} 1 ; \mathrm{r}_{\mathrm{xx}}=0.99, \mathrm{SEM}=5.7 \mathrm{~N}\right)$ and during push-off $\left(\mathrm{F} 3 ; \mathrm{r}_{\mathrm{xx}}=0.99\right.$, $\mathrm{SEM}=4.9 \mathrm{~N}$ ) by recording the highest force observed during the phase (see Figure 1). The weight acceptance rate $\left(r_{\mathrm{xx}}=0.98, \mathrm{SEM}=116 \mathrm{~N} \mathrm{~s}^{-1}\right)$ was calculated as the slope of the force vs. time curve between $10-90 \%$ of the weight acceptance peak force, and, the pushoff rate $\left(\mathrm{r}_{\mathrm{xx}}=0.95, \mathrm{SEM}=115 \mathrm{~N} \mathrm{~s}^{-1}\right)$ was calculated as the slope of the force vs. time curve between $90-10 \%$ of the push-off peak force.

Temporal gait parameters were calculated using the force-time data for each foot. Footground contact time $\left(r_{x x}=0.92, S E M=0.017 \mathrm{~s}\right)$ was the time from initial foot strike of one foot (beginning of force data) until toe-off of the same foot (end of force data). Single-limb support time $\left(r_{\mathrm{xx}}=0.74, \mathrm{SEM}=0.022 \mathrm{~s}\right)$ was determined as the time from toe-off of one foot until foot strike of the same foot. Double-limb support time $\left(r_{x x}=0.69, S E M=0.020 \mathrm{~s}\right)$ was recorded as the time from foot strike of one foot until toe-off of the opposite foot. Stride time $\left(r_{\mathrm{xx}}=0.96, \mathrm{SEM}=0.020 \mathrm{~s}\right)$ was determined as the time duration from foot strike of one 
foot to the next foot strike of the same foot. Then stride rate $\left(r_{x x}=0.96, S E M=1.2\right.$ strides $\min ^{-1}$ ) was calculated by dividing $60 \mathrm{~s} \mathrm{~min}^{-1}$ by the stride time $\left(\mathrm{s} \mathrm{stride}{ }^{-1}\right)$. Spatial gait parameters were calculated using the center of pressure data from each foot. Stride length $\left(r_{\mathrm{Xx}}=0.93, \mathrm{SEM}=0.023 \mathrm{~m}\right)$ was measured as the distance in the sagittal plane from the initial center of pressure at foot strike of one foot to initial center of pressure of the next foot strike of the same foot. Stride width $\left(r_{x x}=0.94\right.$, SEM $\left.0.009 \mathrm{~m}\right)$ was calculated as the average distance in the frontal plane between the right and left foot centers of pressure.

\section{Muscle activation}

Muscle activations of the KE, KF, PF, and DF were assessed using surface electromyography (EMG). Preamplified surface electrodes ( $B \& L$ Engineering, Santa Ana, CA, USA) were placed superficial to the vastus lateralis, medial hamstring, medial gastrocnemius, and tibialis anterior muscles with a ground electrode placed over the proximal head of the fibula. The EMG signal was imported to a personal computer via the data acquisition system where it was sampled at $1 \mathrm{kHz}$, bandpass filtered $(30-500 \mathrm{~Hz})$, fullwave rectified, and integrated every 20 samples. While walking, the peak amplitude of the integrated EMG was determined for each muscle group during both weight acceptance and push-off and was then normalized to the peak EMG from the maximal voluntary contraction.

\section{Statistical Analysis}

Differences between groups for subject age, anthropometrics, physical activity level, SPPB scores, strength and gait measures were assessed using a one-way analysis of variance. The normality of the data were confirmed with boxplots and the Levene statistic. The correlations between KE strength and the strengths of the other muscle groups and the correlations between strength and gait variables were tested using the Pearson product moment statistic. The significance level for all statistical tests was set at $\mathrm{P}<0.05$.

\section{RESULTS}

During the SPPB, low strength women demonstrated 15\% slower habitual gait speed (Table 1). Low strength women had 33\% lower KE maximal torque, 36\% lower PF maximal torque, 34\% lower KE RTD and 30\% lower KF RTD (Figure 2). KE maximal torque was moderately related to KF maximal torque $(r=0.43, \mathrm{P}=0.019)$ and $\mathrm{PF}$ maximal torque $(\mathrm{r}=$ $0.59, \mathrm{P}=0.001)$ but not to DF maximal torque $(\mathrm{r}=0.12, \mathrm{P}=0.294)$. KE peak torque was also related to KE RTD $(r=0.48, P=0.009)$, KF RTD $(r=0.37, \mathrm{P}=0.037)$, DF RTD $(r=$ $0.51, \mathrm{P}=0.006)$ but not to PF RTD $(\mathrm{r}=0.28, \mathrm{P}=0.092)$.

Both groups had equivocal performance while walking at the standard speed with the exception of $15 \%$ longer double-limb support time in low strength subjects (Figure 1A, Table 2). Differences became evident at the maximal speed and when standard speed scores were normalized to maximal performance (Figure 1B, Table 2). Self-selected maximal gait speed was 19\% slower in low strength subjects with 9\% lower F1 and a 33\% lower weight acceptance rate $(\mathrm{P}<0.05)$. This was accompanied by a $7 \%$ slower stride rate, $11 \%$ shorter stride length, $11 \%$ longer foot-ground contact time, and $21 \%$ longer double-limb support time (all $\mathrm{P}<0.05$ ). When walking at the standard speed there was a non-significant trend for higher levels of muscle activation during weight acceptance for low strength subjects (average $35 \pm 12 \%$ vs. $27 \pm 5 \%$ of EMG at MVC, $\mathrm{P}=0.10$ ) that was consistent across all muscle groups. Table 3 illustrates the relationships between lower-limb strengths, vGRF and gait performance. 


\section{DISCUSSION}

The most novel aspect of this study is that it demonstrates that older women with low strength and RTD have correspondingly diminished peak vGRF and rates when walking quickly. Due to the linear relationship between vGRF and walking speed, it then followed that lower-limb weakness was related to slow habitual and maximal walking speeds. Older women with low strength had additional gait deficits including slower maximal stride rates, shorter maximal stride lengths and longer foot-ground contact and double-limb support times. Low strength older women were shown to have diminished force and speed reserve capacities when walking at a standard speed.

\section{Gait}

When examining the supportive forces, temporal, and spatial aspects of gait at the standard speed of $0.8 \mathrm{~m} \mathrm{~s}^{-1}$, there were no distinguishing differences in performance between those with low or normal strength. This is likely due to the selected speed being the slowest minimum speed exhibited by those without disability $[3,21]$ allowing for comparable performance in this sample of healthy, independent livers. As such, at the standard gait speed both groups were operating within their strength capacities and due to the identical workload, the gait response was similar. Only double-limb support time was longer in lowstrength subjects suggesting that support of body weight during stance was shared between legs to a greater extent in those with low strength.

When walking at the maximal speed, low-strength participants experienced diminished F1 and largely reduced weight acceptance rates. The methodology used prevented the recording of the mediolateral and anteroposterior GRF and joint moments during walking and thus comparisons between strength and these measures could not be made. This study did show that a relationship exists between strength and supportive forces, as lower-limb maximal torque and RTD were correlated to the peak vGRF and rate during both weight acceptance and push-off periods. These findings are original and demonstrate one mechanism by which low strength can negatively affect mobility. Due to the positive, linear relationship between peak vGRF and walking [15] and stair climbing [22] speeds, those with poor strength had reduced capacity to walk quickly. Similarly, weight acceptance and push-off rates and walking speed were positively related such that those with poor RTD may have been less likely to generate force rapidly enough to achieve fast walking speeds. In low strength subjects, the reduced RTD and weight acceptance rate potentially explain power's greater influence on functional performance in comparison to strength as has been previously shown $[1,23]$.

What is particularly interesting is that the strength-related deficits in force application appear to occur primarily during weight acceptance when work absorption is occurring and the KE and PF muscles are performing lengthening (eccentric) contractions. When appropriate, muscular strength training of older adults should therefore include exercises with an eccentric component (e.g. isotonic or body weight resistance) as exercises that do not have an eccentric component (e.g. water-based resistance, hydraulic resistance, and isometric exercises) are likely to be less effective at improving mobility.

It is reasonable to speculate that those with low strength modulate force application and gait during maximal walking to match their capacity for force production. For instance, lower maximal stride rate, shorter maximal stride length, and longer foot-ground contact and double-limb support times serve to share the workload of body support between legs and moderate the peak vGRF and rate. This may be a strategy to control balance, maintain a metabolic steady state or to limit neuromuscular fatigue, but the end consequence is reduced walking speed that places weak older women at risk for early mobility disability. 


\section{Strength and Mobility}

The $1.5 \mathrm{Nm} \mathrm{kg}^{-1} \mathrm{KE}$ torque threshold appears to be a good predictor of mobility in older women. Those falling below this threshold exhibited slower chair rise times and had habitual gait speeds below and maximal gait speeds just above the $1.22 \mathrm{~m} \mathrm{~s}^{-1}$ criterion often used to define mobility limitation $[4,24,25]$. What is generally evident is that as lower-limb strength decreases, maximal walking speed decreases in older adults. For example, Rantanen et al. showed that the probability of achieving the $1.22 \mathrm{~m} \mathrm{~s}^{-1}$ criterion increased linearly between KE maximal torques of $1.1 \mathrm{Nm} \mathrm{kg}^{-1}$ to $2.3 \mathrm{Nm} \mathrm{kg}^{-1}$. Hence, the progressive decline in mobility seen with aging is linked to the progressive decline in strength making the maintenance of strength of utmost importance in the prevention of mobility disability.

This study showed that the strengths of the KF, PF, and DF tracked relatively well with KE strength, and in many instances were also related to peak supportive forces and walking performance. It is not surprising that the maximal joint torques and RTDs for a variety of lower-limb muscle groups are collinear with peak vGRF and gait speed. The muscle groups tested in this study work in concert to produce functional movements and exposure to physical activity, disease, age, nutritional and hormonal states, should have led to similar variability in their function. A limitation of this study is that the strengths of the hip flexors, extensors, and abductors were not measured despite their important role in locomotion.

Strength relative to body mass is a modifiable risk factor, influenced largely by participation in resistance exercise and secondly by body composition. In this study the low strength group exhibited higher body mass and BMI, which may have negatively contributed to their low relative strength. Because lower-limb strength relative to mass and vGRF relative to mass were associated with both habitual and maximal gait speed, further study should be dedicated to how excess body mass influences mobility in older adults.

\section{Reserve capacity}

Participants walked at both a standard speed $\left(0.83 \mathrm{~m} \mathrm{~s}^{-1}\right)$ and at their maximal pace which allowed for the determination of speed and force reserve capacities. It is disconcerting that in those with low strength the peak vGRF during walking at the slow, standard speed represented a very high percentage $(91 \%)$ of their maximal force generating capacity. Whereas at the same speed, the peak force generated by older women with normal strength was a lower percentage of their capacity (84\%). Showing similar results during stair climbing, Larsen et al. demonstrated that older adults walking at their freely chosen speed were utilizing $82 \%$ of their peak weight acceptance force whereas young adults were at $63 \%$ of their capacity [22]. In this study the standard gait speed and stride length also represented a greater proportion of maximal capacity in low strength subjects. Thus, even at a minimal gait speed, older women with poor lower-limb strength have little reserve capacity to increase force, stride length, or speed if needed. When operating near maximal capacity during normal locomotion the ability to recover from a loss of balance or move quickly (e.g. avoiding being struck by a vehicle) may therefore be largely compromised.

\section{Conclusions}

In older women, poor strength was associated with diminished peak vertical ground reaction forces and slower habitual and maximal walking speeds which may put low-strength older adults at risk for mobility limitation and disability. For low strength older adults, supportive forces during a slow, standard walking speed represented a higher percentage of maximal force capacity likely increasing fatigue rate, fall risk and the effort of mobility. 


\section{Acknowledgments}

D.P. LaRoche was supported by the National Institute on Aging via NIH Grant L30-AG-038028-01 and E.D. Millett \& R.J. Kralian by the University of New Hampshire. The study sponsors had no involvement in the study design, data collection, analysis and interpretation of data, writing of the manuscript, or in the decision to submit the manuscript for publication.

\section{REFERENCES}

1. Bean JF, Kiely DK, Herman S, Leveille SG, Mizer K, Frontera WR, et al. The relationship between leg power and physical performance in mobility-limited older people. J Am Geriatr Soc. Mar; 2002 50(3):461-7. [PubMed: 11943041]

2. Choquette S, Bouchard DR, Doyon CY, Senechal M, Brochu M, Dionne IJ. Relative strength as a determinant of mobility in elders 67-84 years of age. a nuage study: nutrition as a determinant of successful aging. J Nutr Health Aging. 2010; 14(3):190-5. [PubMed: 20191251]

3. Lauretani F, Russo CR, Bandinelli S, Bartali B, Cavazzini C, Di Iorio A, et al. Age-associated changes in skeletal muscles and their effect on mobility: an operational diagnosis of sarcopenia. $\mathrm{J}$ Appl Physiol. Nov; 2003 95(5):1851-60. [PubMed: 14555665]

4. Manini TM, Visser M, Won-Park S, Patel KV, Strotmeyer ES, Chen H, et al. Knee extension strength cutpoints for maintaining mobility. J Am Geriatr Soc. Mar; 2007 55(3):451-7. [PubMed: 17341251]

5. AGS. Guideline for the prevention of falls in older persons. American Geriatrics Society, British Geriatrics Society, and American Academy of Orthopaedic Surgeons Panel on Falls Prevention. J Am Geriatr Soc. May; 2001 49(5):664-72. [PubMed: 11380764]

6. Pijnappels M, Bobbert MF, van Dieen JH. Push-off reactions in recovery after tripping discriminate young subjects, older non-fallers and older fallers. Gait Posture. Jun; 2005 21(4):388-94. [PubMed: 15886128]

7. LaRoche DP, Cremin KA, Greenleaf B, Croce RV. Rapid torque development in older female fallers and nonfallers: a comparison across lower-extremity muscles. J Electromyogr Kinesiol. Jun; 2010 20(3):482-8. [PubMed: 19782579]

8. Cawthon PM, Fox KM, Gandra SR, Delmonico MJ, Chiou CF, Anthony MS, et al. Do muscle mass, muscle density, strength, and physical function similarly influence risk of hospitalization in older adults? J Am Geriatr Soc. Aug; 2009 57(8):1411-9. [PubMed: 19682143]

9. Laukkanen P, Heikkinen E, Kauppinen M. Muscle strength and mobility as predictors of survival in 75-84-year-old people. Age Ageing. Nov; 1995 24(6):468-73. [PubMed: 8588534]

10. Guralnik JM, Simonsick EM, Ferrucci L, Glynn RJ, Berkman LF, Blazer DG, et al. A short physical performance battery assessing lower extremity function: association with self-reported disability and prediction of mortality and nursing home admission. J Gerontol. Mar; 1994 49(2):M85-94. [PubMed: 8126356]

11. Hughes VA, Frontera WR, Wood M, Evans WJ, Dallal GE, Roubenoff R, et al. Longitudinal muscle strength changes in older adults: influence of muscle mass, physical activity, and health. J Gerontol A Biol Sci Med Sci. May; 2001 56(5):B209-17. [PubMed: 11320101]

12. Guralnik JM, Ferrucci L, Pieper CF, Leveille SG, Markides KS, Ostir GV, et al. Lower extremity function and subsequent disability: consistency across studies, predictive models, and value of gait speed alone compared with the short physical performance battery. J Gerontol A Biol Sci Med Sci. Apr; 2000 55(4):M221-31. [PubMed: 10811152]

13. Ploutz-Snyder LL, Manini T, Ploutz-Snyder RJ, Wolf DA. Functionally relevant thresholds of quadriceps femoris strength. J Gerontol A Biol Sci Med Sci. Apr; 2002 57(4):B144-52. [PubMed: 11909879]

14. Cress ME, Meyer M. Maximal voluntary and functional performance levels needed for independence in adults aged 65 to 97 years. Phys Ther. Jan; 2003 83(1):37-48. [PubMed: 12495411]

15. Keller TS, Weisberger AM, Ray JL, Hasan SS, Shiavi RG, Spengler DM. Relationship between vertical ground reaction force and speed during walking, slow jogging, and running. Clin Biomech (Bristol, Avon). Jul; 1996 11(5):253-9. 
16. Winter DA. Overall principle of lower limb support during stance phase of gait. J Biomech. 1980; 13(11):923-7. [PubMed: 7275999]

17. Hof AL. On the interpretation of the support moment. Gait Posture. Dec; 2000 12(3):196-9. [PubMed: 11154929]

18. Nilsson J, Thorstensson A. Ground reaction forces at different speeds of human walking and running. Acta Physiol Scand. Jun; 1989 136(2):217-27. [PubMed: 2782094]

19. Topolski TD, LoGerfo J, Patrick DL, Williams B, Walwick J, Patrick MB. The Rapid Assessment of Physical Activity (RAPA) among older adults. Prev Chronic Dis. Oct.2006 3(4):A118. [PubMed: 16978493]

20. Stacoff A, Diezi C, Luder G, Stussi E, Kramers-de Quervain IA. Ground reaction forces on stairs: effects of stair inclination and age. Gait Posture. Jan; 2005 21(1):24-38. [PubMed: 15536031]

21. Bouchard DR, Janssen I. Dynapenic-obesity and physical function in older adults. J Gerontol A Biol Sci Med Sci. Jan; 2010 65(1):71-7. [PubMed: 19887536]

22. Larsen AH, Puggaard L, Hamalainen U, Aagaard P. Comparison of ground reaction forces and antagonist muscle coactivation during stair walking with ageing. J Electromyogr Kinesiol. Mar 13.2007

23. Bean JF, Leveille SG, Kiely DK, Bandinelli S, Guralnik JM, Ferrucci L. A comparison of leg power and leg strength within the InCHIANTI study: which influences mobility more? J Gerontol A Biol Sci Med Sci. Aug; 2003 58(8):728-33. [PubMed: 12902531]

24. Rantanen T, Guralnik JM, Izmirlian G, Williamson JD, Simonsick EM, Ferrucci L, et al. Association of muscle strength with maximum walking speed in disabled older women. Am J Phys Med Rehabil. Jul-Aug; 1998 77(4):299-305. [PubMed: 9715919]

25. Stenholm S, Rantanen T, Alanen E, Reunanen A, Sainio P, Koskinen S. Obesity history as a predictor of walking limitation at old age. Obesity (Silver Spring). Apr; 2007 15(4):929-38. [PubMed: 17426328] 


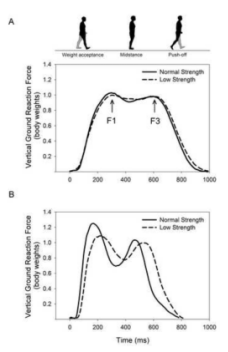

Figure 1.

Comparison of vertical ground reaction force relative to body mass between low and normal strength groups at a standard speed of $0.8 \mathrm{~m} \mathrm{~s}^{-1}$ (A) and at participants' self-selected maximal speed (B). Solid line represents the mean response of those with normal knee extensor strength $\left(>1.5 \mathrm{Nm} \mathrm{kg}^{-1}\right)$ and dashed line represents the mean response of those with low knee extensor strength $\left(<1.5 \mathrm{Nm} \mathrm{kg}^{-1}\right)$. F1 = weight acceptance peak force, $\mathrm{F} 3=$ push-off peak force. 

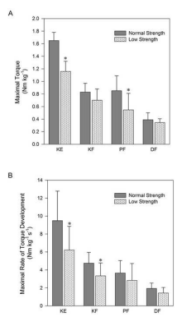

Figure 2.

Comparison of maximal torque (A) and maximal rate of torque development (B) of the lower-limb prime movers between those with low $\left(<1.5 \mathrm{Nm} \mathrm{kg}^{-1}\right)$ and normal $(>1.5 \mathrm{Nm}$ $\left.\mathrm{kg}^{-1}\right)$ knee extensor strength. Values are mean $\pm \mathrm{SD} . *$ difference between groups, $\mathrm{P}$ $<0.05$. KE, knee extensors; KF, knee flexors; PF, plantarflexors; DF, dorsiflexors 
Table 1

Participant descriptive characteristics

\begin{tabular}{lccc}
\hline & Low Strength & Normal Strength & P \\
\hline Age (yr) & $71.2 \pm 4.3$ & $72.1 \pm 5.2$ & 0.662 \\
Mass (kg) & $68.3 \pm 9.3$ & $61.0 \pm 6.2 *$ & 0.037 \\
Height (m) & $1.58 \pm 0.08$ & $1.62 \pm 0.06$ & 0.266 \\
Body Mass Index $\left(\mathrm{kg} \mathrm{m}^{-2}\right)$ & $26.9 \pm 3.9$ & $23.3 \pm 2.7 *$ & 0.018 \\
Strength Physical & $1.6 \pm 1.3$ & $2.3 \pm 1.2$ & 0.205 \\
Activity Score & & & \\
Aerobic Physical & $4.9 \pm 1.5$ & $5.9 \pm 1.4$ & 0.110 \\
Activity Score & & & \\
SPPB Score & $10.7 \pm 1.3$ & $11.4 \pm 0.7$ & 0.141 \\
Balance Score & $3.8 \pm 0.6$ & $3.9 \pm 0.3$ & 0.491 \\
Habitual Gait Speed $\left(\mathrm{m} \mathrm{s}^{-1}\right)$ & $1.12 \pm 0.19$ & $1.32 \pm 0.25 *$ & 0.036 \\
Chair Rise Time (s) & $11.5 \pm 1.5$ & $10.3 \pm 1.4$ & 0.063 \\
\hline
\end{tabular}

Values are mean $\pm \mathrm{SD}$

SPPB $=$ Short Physical Performance Battery; the overall score is reported followed by the individual performances for each portion of the test.

* $=$ difference between groups, $\mathrm{P}<0.05$ 


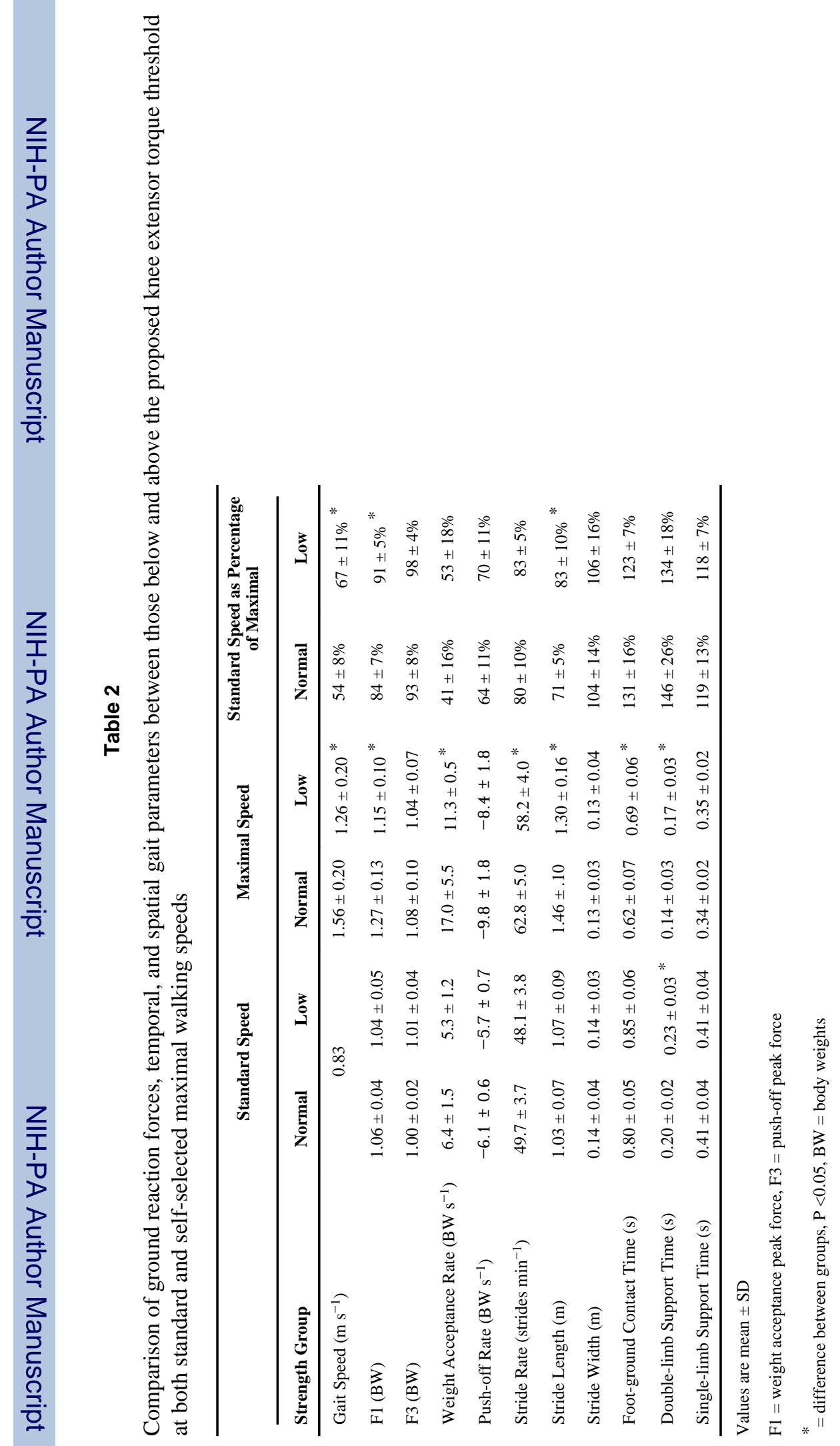

Gait Posture. Author manuscript; available in PMC 2012 April 1. 


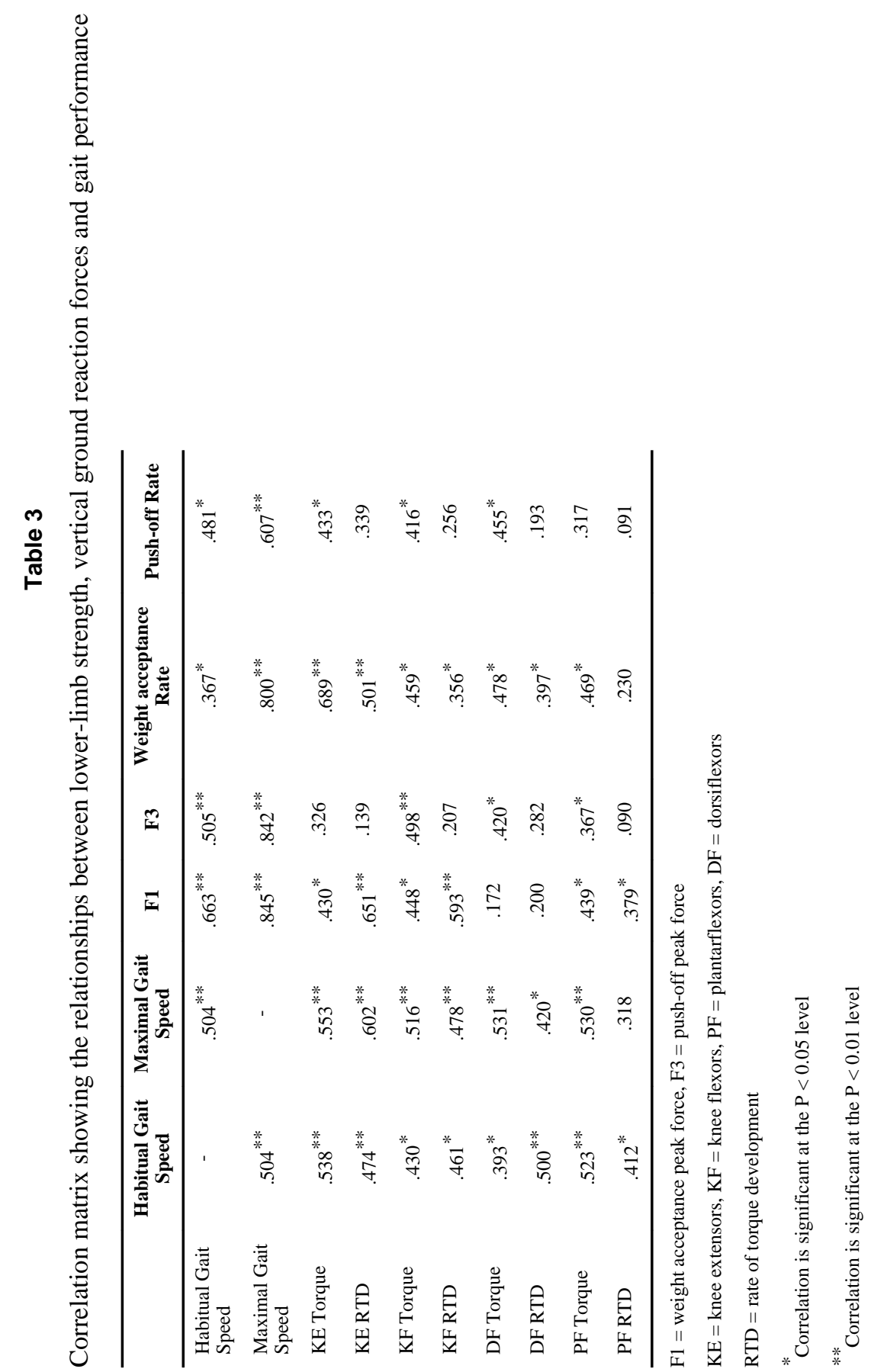

